\title{
Índice de mobilidade para transporte urbano de carga
}

\author{
Mobility index for urban freight transportation
}

Cynthia Vargas Cuchava Rocha[a] iD, Vania Barcellos Gouvea Campos[a],

Renata Albergaria de Mello Bandeira[a]

[a] Instituto Militar de Engenharia (IME), Rio de Janeiro, RJ, Brasil

Como citar: Rocha, C. V. C., Campos, V. B. G., \& Bandeira, R. A. M. (2019). Índice de mobilidade para transporte urbano de carga. urbe. Revista Brasileira de Gestão Urbana, v.11, e20180204. DOI https://doi.org/10.1590/2175-3369.011.e20180204

\section{Resumo}

O presente artigo propõe um índice de mobilidade para Transporte Urbano de Carga (TUC), que tem como objetivo subsidiar decisões sobre ações a serem implantadas, visando uma melhor circulação em regiões urbanas. Índices de mobilidade têm sido propostos para avaliação do deslocamento urbano de pessoas, porém, em relação à movimentação da carga pouco tem sido estudado no contexto de regiões urbanas. Para definição da composição do índice de mobilidade do TUC foi realizada uma pesquisa bibliográfica visando identificar as principais ações relacionadas com medidas físicas, operacionais e de planejamento para mitigar as externalidades do TUC. A partir desta revisão bibliográfica foi definido um conjunto de indicadores e subindicadores para composição do índice. Na formulação do índice, empregou-se o princípio de agregação de indicadores e, para definição dos pesos dos indicadores, utilizou-se um método de avaliação multicritério. O índice foi aplicado no centro da cidade de Niterói (RJ) e o valor resultante do índice, que avalia todas as condições existentes para o TUC, indicou que a área em análise tinha baixa mobilidade para transporte urbano de carga, carecendo de aplicação de medidas que revertam esse quadro.

Palavras-chave: Mobilidade. Transporte Urbano de Carga (TUC). Índice. Indicadores.

\section{Abstract}

This paper proposes a mobility index for urban freight transportation (UFT), with the purpose of subsidizing decisions related to the implementation of actions and measures that may lead to improvements in the mobility level in a certain city area. Mobility indices have been priory proposed for assessing and monitoring the movement of people within city borders, but this topic has been understudied in the context urban freight transportation. Therefore, in order to develop a mobility index for UFT, we carried a literature review to identify the main actions that could be implemented by the government in order to mitigate externalities caused by urban freight transportation. Based on the result of this literature review, a set of indicators to compose an mobility index for freight transportation was proposed. We used the principle of aggregating indicators to formulate the proposed index and, to define the weight of each indicator, we opted to use a

CVCR é engenheira civil, mestre em Engenharia de Transportes, e-mail: cvrengenharia@gmail.com

VBGC é arquiteta urbanista, mestre em Engenharia de Transportes, doutora em Engenharia de Produção, e-mail: vania@ime.eb.br

RAMB é engenheira de fortificação e construção, doutora em Engenharia de Transportes, e-mail: re.albergaria@gmail.com 
multicriteria decision aid method. The proposed index was applied in the city center of Niterói/RJ. The resulting value for the UFT mobility index, in this application, indicates that this area does not have a good mobility level for urban freight transportation, lacking implementing measures to reverse this situation.

Keywords: Mobility. Urban freight transport. Index. Indicators (KPI).

\section{Introdução}

Em 2015, 54,5\% da população mundial vivia em áreas urbanas (Banco Mundial, 2015), e a previsão é de que este número chegue a $70 \%$ até 2050 (ONU, 2013). Este rápido processo de urbanização, associado a práticas logísticas como o just-in-time e o aumento do comércio eletrônico business-to-consumer (B2C), implica em um acréscimo significativo na demanda pelo transporte urbano de carga (TUC) (Domínguez et al., 2012). Contudo, o TUC tem impacto significativo em relação a aspectos socioeconômicos e ambientais nas cidades, sobretudo com relação à poluição sonora, atmosférica e à emissão de gases de efeito estufa, além de custos, segurança e no congestionamento do tráfego (Roumboutsos et al., 2014).

Esses desafios referentes ao TUC são comuns a todas grandes cidades (Lindhome \& Behrends, 2012). Entretanto, as autoridades públicas, tradicionalmente, não abordam com a devida atenção as questões relacionadas ao transporte de carga na cidade, exceto por algumas soluções, como regulamentação de estacionamentos, restrições de acesso e períodos de operação (Crainic et al, 2004). Em geral, mesmo quando as autoridades públicas estão conscientes do impacto negativo da má gestão do transporte de carga, as questões relacionadas ao TUC ainda não são bem compreendidas nem quantificadas, não havendo assim conhecimento suficiente sobre como lidar com o problema de forma eficiente (Lindholm \& Blinge, 2014). Logo, é relevante o desenvolvimento de ferramentas que auxiliem a administração pública local no planejamento do transporte urbano, considerando a mobilidade de carga.

Neste contexto, destacam-se os indicadores e índices de mobilidade, que possibilitam a avaliação e monitoramento da mobilidade urbana à medida que permitem que ações mais eficientes e coerentes com a condição identificada sejam tomadas para minimizar os impactos e até prevenir externalidades (Abdala e Pasqualeto, 2013). Porém, em grande parte dos estudos desenvolvidos na área de mobilidade urbana, os indicadores propostos estão atrelados às questões de operação e infraestrutura de transporte urbano de passageiros, deixando de considerar o TUC (Costa, 2008; Banister et al., 2000; Campos \& Ramos, 2005; Lautso, 2004; Gayda et al. 2005; Minken et al. 2001; Campos, 2006; WBCSD, 2004).

Portanto, o presente artigo propõe um índice de mobilidade do transporte urbano de carga (IMTUC), que permite avaliar a mobilidade de uma região em relação ao TUC. Assim, o índice proposto pode subsidiar a administração pública local a tomar decisões sobre o planejamento de áreas urbanas para este tipo de transporte, sendo utilizado, por exemplo, como forma de avaliar se determinada área tem condições de receber um novo polo gerador de viagens (PGV) ou mesmo novas áreas comerciais. 0 método desenvolvido permite identificar medidas a serem implantadas visando uma melhor circulação de veículos de carga e menos impactos na região.

Após esta introdução, o artigo está dividido em sete seções. Na Seção 2, apresenta-se uma síntese da revisão bibliográfica sobre as soluções aplicadas em diversas cidades do mundo, a fim de mitigar os impactos ocasionados pelo TUC. A Seção 3 propõe um conjunto de indicadores, que são a base para o desenvolvimento do IMTUC. 0 procedimento para determinação do IMTUC é apresentado na Seção 4 . A Seção 5 apresenta a sua aplicação na região central da cidade de Niterói, Rio de Janeiro, sendo os resultados analisados na Seção 6. A Seção 7 traz as conclusões, limitações e sugestões para trabalhos futuros.

\section{Ações para mitigação do impacto do TUC}

Segundo Visser et al. (1999), as soluções para a mitigação dos impactos gerados pelo TUC em determinada área podem ser: (i) ações restritivas, que têm como objetivo desviar a produção do curso que seguiria se não fosse obstruída, sendo que essa produção abrange também o comércio e transportes; ou (ii) medidas. Estas 
medidas podem ser: de cunho preventivo, visando evitar um impacto; minimizadoras, com o objetivo de reduzir um impacto já existente; ou compensatórias, que compensam um impacto que é inevitável acontecer (Agência Portuguesa do Meio Ambiente, 2011).

Visando identificar as principais ações adotadas para mitigar os problemas derivados do TUC, realizou-se uma revisão bibliográfica sobre o tema, com abrangência nacional e internacional. Como resultado, foram levantados 26 trabalhos que estudam ações para melhorar o TUC em diversas partes do mundo: Ogden (1992), Visser et al. (1999), Pivo et al. (2002), Transport Research \& Innovation Portal (2004), Dutra (2004), Crainic et al. (2004), Emberger (2004), Muñuzuri et. al, (2005); Sinarimbo (2005), Silva (2006), Bestufs (2008), C-LIEGE (2010), Betanzo-Quezada e Romero (2010), Russo e Comi (2011), IMTT (2011), Silva (2012), Muñuzuri, J., Cortés, P., Guadix, J., \& Onieva, L. (2012), Ballantyne et al. (2013), Holguín-Veras (2015), Leonardi et. al. (2014), Gatta e Marcucci (2014), Nuzzolo e Comi (2014), Bozzo et al. (2014), Oliveira (2015), Megacity Logistics (2015) e Lagorio e Golini (2016). A partir da análise dos trabalhos, foram identificadas 54 questões físicas, operacionais e de planejamento relacionadas a ações que poderiam ser aplicadas, a fim de mitigar/minimizar os problemas ocasionados pelo TUC.

Essas 54 questões foram categorizadas com base na classificação proposta por Muñuzuri et al. (2005): (i) Infraestrutura pública, que se refere à construção de nova infraestrutura ou adaptação da existente para facilitar a logística urbana; (ii) Gestão do uso do solo, que abrange as alocações de áreas a serem usadas para o TUC e determinação de regulamentações, que, de maneira direta ou indireta, possam afetar a implantação de novas edificações em determinadas áreas ou até mesmo as já existentes; (iii) Gestão de tráfego, que aborda a reorganização do fluxo dos veículos de carga nas localidades em que o tráfego é denso; (iv) Sanções e promoções: que se referem, respectivamente, à obrigação e ao estímulo à aplicação de determinadas soluções; e (v) Condições de acesso, que envolve restrições espaciais e de tempo. A Tabela 1 apresenta as 54 questões identificadas na literatura, classificadas nesses cinco grupos, além de descrever o número de vezes que cada uma destas foi citada.

Tabela 1 - Questões citadas nas bibliografias relacionadas a ações para mitigação e minimização de problemas com TUC

\begin{tabular}{|c|c|c|}
\hline Categorias & Soluções & Citações \\
\hline \multirow[t]{11}{*}{ Infraestrutura pública } & Geometria da via & 6 \\
\hline & Sinalização da via & 5 \\
\hline & Equipamentos urbanos e paisagismo & 3 \\
\hline & Uso do transporte público para carga & 6 \\
\hline & Uso de portos e ferrovias para transbordo & 3 \\
\hline & Transporte subterrâneo & 6 \\
\hline & Condição do pavimento da via & 4 \\
\hline & Ruas de duplo sentido de fluxo & 2 \\
\hline & Transbordo em periferia & 5 \\
\hline & Ruas de serviço para baias & 4 \\
\hline & Faixas de acordo com zoneamento & 2 \\
\hline \multirow[t]{12}{*}{ Gestão do uso do solo } & PGV com estacionamento para carga & 4 \\
\hline & PGV com acesso exclusivo para carga & 2 \\
\hline & PGV com rampa e elevadores para carga & 3 \\
\hline & Faixa de rolamento multiuso (estacionamento conforme hora) & 8 \\
\hline & Pontos coletivos de coleta e entrega de mercadorias & 9 \\
\hline & Baias no fim do quarteirão ou no máximo $500 \mathrm{~m}$ do PGV & 5 \\
\hline & Baias com dimensão de veículos maiores & 6 \\
\hline & Comercio próximo ao centro de distribuição & 15 \\
\hline & Centros de consolidação de mercadorias & 10 \\
\hline & Baias de carga e descarga ao longo da via & 11 \\
\hline & Baias de carga nas vias adjacentes as ruas principais & 6 \\
\hline & Áreas não favoráveis à passagem de veículos & 5 \\
\hline \multirow[t]{6}{*}{ Gestão do tráfego } & Classificação dos transportadores & 3 \\
\hline & Faixas específicas para carga & 3 \\
\hline & Classificação de zonas de carga & 3 \\
\hline & Entregas coletivas conforme as áreas & 9 \\
\hline & Entregas com horários programados & 11 \\
\hline & Monopolização das entregas & 2 \\
\hline
\end{tabular}




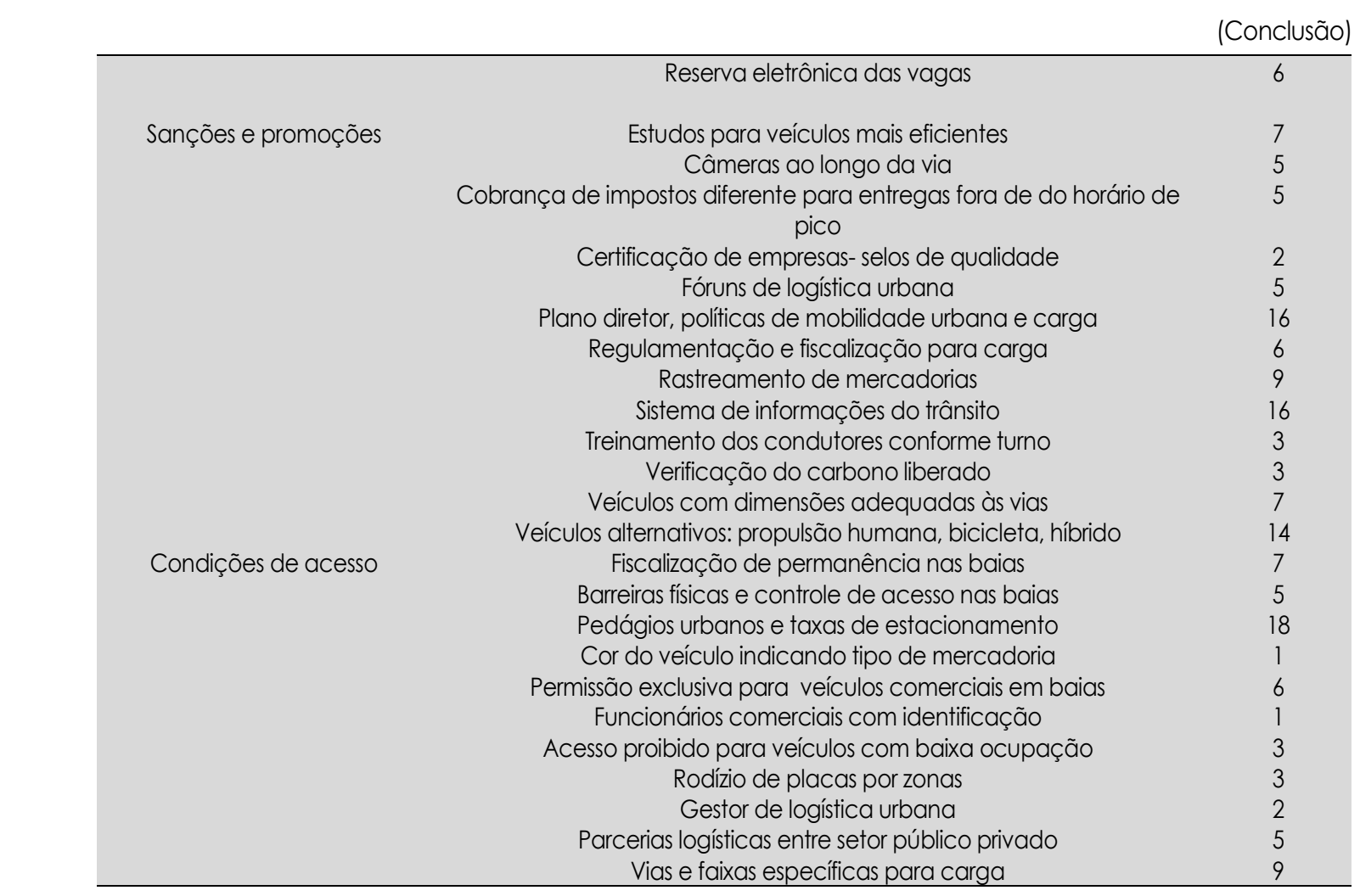

Fonte: Elaborada pelos autores.

\section{Proposta de indicadores para o Índice de Mobilidade para TUC}

A implantação de ações para mitigação do impacto do TUC deve ser fruto de esforços conjuntos entre o setor público e privado (Macharis \& Melo, 2011). Entretanto, cabe ao poder público o maior papel: buscar formas de planejar a cidade e promover ações para que isso ocorra (Muñuzuri et al., 2005).

Baseado na premissa de que o poder público deve aplicar e estimular ações para a mitigação de problemas relacionados ao TUC e, tendo como base as questões apresentadas na Tabela 1, propõe-se um conjunto de indicadores e subindicadores para avaliar a mobilidade do transporte urbano de carga, sob a ótica do poder público. Esses são relacionados às ações que podem ser implantadas pelo poder público para mitigar os problemas causados pelo TUC e em questões relacionadas à ocupação do solo e condições das vias e calçadas (para veículos alternativos de propulsão humana, conhecidos como carrinhos de carga), visando à atuação do poder público na mitigação dos problemas de circulação de TUC na região. Esse conjunto de indicadores/subindicadores é a base para a estrutura do índice proposto neste artigo.

Verificou-se que, das 54 questões apresentadas na Tabela 1, 21 se relacionam a ações para mitigação e minimização de problemas com TUC, que podem ser implantadas pelo poder público. Inicialmente, 17 destas questões foram adotadas como subindicadores: (i) Classificação de zonas de carga; (ii) monopolização de entregas; (iii) pedágio urbano; (iv) reserva eletrônica de vagas de carga e descarga; (v) fiscalização eletrônica de acesso e baias; (vi) faixas de rolamento reversíveis para estacionamento e circulação; (vii) sistema de informação do trânsito; (viii) transporte público compartilhado com carga; (ix) taxa de estacionamento; (x) PVG com acesso exclusivo a carga; (xi) transbordo em periferia; (xii) baias ao longo da via; (xiii) baias em ruas de serviço; (xiv) condição do pavimento da via; (xv) estabelecimento de densidade mínima de ocupação de veículo; (xvi) distância entre áreas de comércio e centros de distribuição; e (xvii) número de baias dentro de 500m do PVG). A questão "PGV estacionamento exclusivo para carga" deu origem ao subindicador Empreendimentos com estacionamento exclusivos para carga. Ainda, com base nas outras quatro questões (Áreas não favoráveis à passagem de veículos, geometria da via, Equipamentos urbanos e veículos alternativos), foram propostos oito subindicadores: esquinas com ângulos adequados, inclinação da via, largura da via, número de faixas de rolamento, largura livre de calçada, obstrução nas calçadas e rampas 
entre calçadas e via e regularidade da pavimentação da calçada. Além disto, em relação à ocupação do solo, foram propostos os indicadores: densidade comercial e densidade residencial.

Esta proposta inicial de 28 indicadores foi apresentada a cinco acadêmicos especialistas na área de transporte das mais diversas regiões do país, tendo estes o título de doutor e mais de 10 anos de experiência. Os especialistas validaram a proposta, porém sugeriram a agregação de mais um indicador: permissão de trânsito de veículos de carga em faixas exclusiva de ônibus ${ }^{1}$. Desse modo, foram propostos 29 subindicadores, agrupados em cinco categorias de indicadores: condições de acesso, gestão do fluxo de tráfego, uso do solo, transporte motorizado e transporte não motorizado. Destaca-se que, no transporte motorizado, considerouse o transporte realizado por veículos de carga, mais precisamente os veículos urbanos de carga (VUC), que ainda representam a maior parte da distribuição em lojas, ou seja, no varejo. No contexto do transporte não motorizado ${ }^{2}$, foi caracterizada a entrega que ocorre do caminhão à loja, utilizando o carrinho de carga, por exemplo, quando o veículo de carga está em uma baia de uma via de auxiliar e não na principal onde está o local da entrega, ou então, quando está numa baia e distribui para várias lojas próximas.

Na proposta de indicadores/subindicadores, buscou-se englobar questões diretamente relacionadas à circulação dos veículos de carga, visando assim minimizar o impacto e, até mesmo, reduzir circulação destes. Também foram considerados indicadores que evidenciem se a área já é densamente ocupada, ou não, pelo comércio. Tais condições, associadas às características das vias existentes, podem não suportar a implantação de novos empreendimentos comerciais. Além disso, houve uma preocupação de incluir indicadores que evidenciassem a possibilidade de transporte não-motorizado (considerando da descarga até a entrega ao cliente final) nas próprias calçadas e a facilidade de carga/descarga nas mesmas. Essas são questões relacionadas à redução de veículos em circulação e fazem parte de propostas de alguns autores pesquisados, como Pivo et. al (2002) e Silva (2006).

Enfim, a Tabela 2 apresenta a proposta de indicadores de mobilidade e seus subindicadores, além da indicação de como estes devem ser medidos e onde podem ser obtidos os dados para sua quantificação.

Tabela 2 - Proposta de indicadores e subindicadores

\begin{tabular}{|c|c|c|c|}
\hline Indicadores & Subindicadores & $\begin{array}{l}\text { Fonte de } \\
\text { dados }\end{array}$ & Como medir \\
\hline $\begin{array}{l}\text { Condições de } \\
\text { acesso }\end{array}$ & $\begin{array}{l}\text { Classificação de zona de } \\
\text { carga } \\
\text { Estabelecimento de } \\
\text { densidade mínima de } \\
\text { ocupação do veículo }\end{array}$ & $\begin{array}{l}\text { IN LOCO } \\
\text { Leis e } \\
\text { normativas }\end{array}$ & $\begin{array}{l}\text { Verificar a existência de placas indicando áreas de carga, instrução } \\
\text { normativas, regulamentação sendo ela em plano diretor, planos de } \\
\text { mobilidade ou outro tipo de estipulação do município. } \\
\text { Verificar em normativas e leis a estipulação de densidade mínima de } \\
\text { ocupação do veículo }\end{array}$ \\
\hline & $\begin{array}{l}\text { Pedágio urbano } \\
\text { Reserva eletrônica de vagas } \\
\text { de carga e descarga }\end{array}$ & $\begin{array}{l}\text { IN LOCO } \\
\text { IN LOCO }\end{array}$ & $\begin{array}{c}\text { Verificar junto a empreendimentos comerciais se o sistema de } \\
\text { entregas dos empreendimentos da região são realizados pela } \\
\text { mesma empresa. } \\
\text { Verificar se é feita a cobrança de pedágios. } \\
\text { Verificar a existência de reserva eletrônica de vagas em áreas } \\
\text { públicas. }\end{array}$ \\
\hline $\begin{array}{l}\text { Gestão do } \\
\text { Tráfego }\end{array}$ & $\begin{array}{l}\text { Fiscalização eletrônica de } \\
\text { acesso e baias }\end{array}$ & IN LOCO & $\begin{array}{l}\text { Analisar presença de câmera ao longo do segmento que controle o } \\
\text { acesso nas baias. }\end{array}$ \\
\hline
\end{tabular}

\footnotetext{
${ }^{1}$ Destaca-se que compartilhamentos de corredores e/ou faixas exclusivas de ônibus, inclusive para transportes de passageiros, podem levar à redução de sua capacidade ao longo do dia e, consequentemente, de sua eficácia (Paradeda et al., 2014). Porém, esta medida contribui para a melhoria da mobilidade para o TUC, de modo que se optou por manter esse indicador, ressaltando-se a necessidade de avaliar o seu impacto para a mobilidade urbana em geral.

${ }^{2}$ Considerou-se que o transporte por bicicletas, por exemplo, está mais relacionado a pequenas entregas em domicílios escritórios etc, no chamado last mile (última milha) do TUC.
} 
(Conclusão)

\begin{tabular}{|c|c|c|c|}
\hline & $\begin{array}{c}\text { Faixas de rolamento reversíveis } \\
\text { para estacionamento e } \\
\text { circulação }\end{array}$ & IN LOCO & $\begin{array}{c}\text { Verificar a existência de faixas de rolamento que podem } \\
\text { ser usadas para carga e descarga. }\end{array}$ \\
\hline & $\begin{array}{l}\text { Permissão de trânsito em faixa } \\
\text { de ônibus }\end{array}$ & IN LOCO & $\begin{array}{l}\text { Verificar a existência de faixas exclusivas de transporte } \\
\text { público que podem, em horários específicos, ser usadas } \\
\text { para o fluxo de veículos de carga. }\end{array}$ \\
\hline & $\begin{array}{l}\text { Sistema de informação do } \\
\text { trânsito }\end{array}$ & IN LOCO & $\begin{array}{c}\text { Verificar a existência de sistema de informações do } \\
\text { trânsito em tempo real. }\end{array}$ \\
\hline & $\begin{array}{l}\text { Transporte público } \\
\text { compartilhado para carga }\end{array}$ & IN LOCO & $\begin{array}{c}\text { Verificar se o transporte público é empregado para } \\
\text { transporte de carga. }\end{array}$ \\
\hline & $\begin{array}{l}\text { Taxa de estacionamento da } \\
\text { baia }\end{array}$ & IN LOCO & Verificar se é feita a cobrança de taxas para estacionar. \\
\hline Uso do solo & Densidade comercial & IN LOCO & $\begin{array}{l}\text { Verificar o total de faixa de empreendimentos comerciais } \\
\text { no segmento. }\end{array}$ \\
\hline & Densidade residencial & IN LOCO & $\begin{array}{c}\text { Verificar o total de faixa de residências na extensão do } \\
\text { segmento. }\end{array}$ \\
\hline & $\begin{array}{l}\text { Distância entre áreas de } \\
\text { comercio e centros de } \\
\text { distribuição }\end{array}$ & Mapas e IN LOCO & $\begin{array}{l}\text { Verificar em mapa a distância entre as áreas comerciais } \\
\text { e os centros de distribuição }\end{array}$ \\
\hline & $\begin{array}{c}\text { Empreendimentos com } \\
\text { estacionamentos exclusivos } \\
\text { para carga }\end{array}$ & IN LOCO & $\begin{array}{c}\text { In Loco verificar a exigência de estacionamento } \\
\text { exclusivo para carga. }\end{array}$ \\
\hline & $\begin{array}{c}\text { PGV com acesso exclusive para } \\
\text { carga }\end{array}$ & $\begin{array}{l}\text { IN LOCO Planos de } \\
\text { uso e ocupação do } \\
\text { solo }\end{array}$ & $\begin{array}{l}\text { In Loco verificar PGVs que possuem acesso exclusivo } \\
\text { para carga e em planos de uso e ocupação do solo }\end{array}$ \\
\hline & Transbordo em periferia & Mapas e IN LOCO & $\begin{array}{c}\text { Verificar no plano diretor a determinação de áreas de } \\
\text { transbordo }\end{array}$ \\
\hline $\begin{array}{l}\text { Transporte } \\
\text { motorizado }\end{array}$ & $\begin{array}{l}\text { Baias ao longo da via } \\
\text { (segmento analisado) }\end{array}$ & IN LOCO & $\begin{array}{c}\text { Verificar a presença de baias para carga e descarga ao } \\
\text { longo do segmento. }\end{array}$ \\
\hline & Baias em ruas de serviço & IN LOCO & Verificar a presença de baias em ruas de serviço. \\
\hline & Condições dos pavimentos & IN LOCO & Analisar a situação do pavimento do segmento. \\
\hline & $\begin{array}{l}\text { Esquinas com ângulos } \\
\text { adequados }\end{array}$ & IN LOCO & $\begin{array}{c}\text { Analisar se os ângulos das esquinas são adequados (não } \\
\text { obtusos ou muito fechados). }\end{array}$ \\
\hline & Inclinação da via & IN LOCO & Analisar a inclinação do segmento. \\
\hline & Largura da via & IN LOCO & Analisar a largura efetiva da via. \\
\hline & Número de faixas de rolamento & IN LOCO & Analisar número de faixas por sentido de rolamento. \\
\hline Transporte não & Largura livre da calçada & IN LOCO & Verificar a largura livre de obstáculos. \\
\hline Motorizado & $\begin{array}{l}\text { Número de baias dentro de } \\
500 \mathrm{~m} \text { do PGV }\end{array}$ & IN LOCO & Verificar o número de baias em um raio de $500 \mathrm{~m}$ dos PGV \\
\hline & Obstrução nas calçadas & IN LOCO & $\begin{array}{c}\text { Analisar a locação dos equipamentos urbanos (bancos, } \\
\text { pontos de ônibus, lixeiras), bancas de jornal e lojas que } \\
\text { expõem mercadorias nas calçadas. }\end{array}$ \\
\hline & $\begin{array}{l}\text { Rampas entre calçada e via } \\
\text { Regularidade da pavimentação } \\
\text { da calçada }\end{array}$ & $\begin{array}{l}\text { IN LOCO } \\
\text { IN LOCO }\end{array}$ & $\begin{array}{l}\text { Visualizar a presença de rampas. } \\
\text { Analisar a qualidade da pavimentação das calcadas. }\end{array}$ \\
\hline
\end{tabular}

Fonte: Elaborada pelos autores.

\section{Procedimento para determinação do índice de mobilidade de transporte urbano de carga em uma região}

Nesta seção, é apresentado o procedimento para determinação do índice de mobilidade para o transporte urbano de carga (IMTUC), que pode ser aplicado para região de uma cidade, de modo a possibilitar a identificação dos pontos que devem ser melhorados a fim de favorecer a mobilidade urbana de modo geral (cargas, veículos de passeio e coletivos, pedestres e ciclistas). 0 procedimento proposto é dividido em três etapas, descritas a seguir. 


\section{Ełapa 1: Determinação da área de estudo}

O objetivo desta etapa consiste na preparação da base de dados, sendo assim necessária a realização das seguintes atividades: (i) obtenção de mapa de arruamento da cidade; (ii) identificação das áreas de maior concentração de comércio; (iii) delimitação da área a ser estudada; (iv) pesquisa de dados censitários, leis e normativas municipais, plano diretor e de uso do solo relacionada à área em análise, para estabelecimento de parâmetros dos indicadores.

A delimitação da área a ser estudada baseia-se em definir qual a região da cidade que concentra maior atividade comercial (quantidade e variedades de ramos). Uma vez definida a área de estudo (ruas e quadras), define-se onde estão localizados PGV, quais as ruas da zona de comércio da cidade que serão analisadas, e quais são os principais segmentos viários.

\section{Ełapa 2: Medição e quantificação dos indicadores na área de estudo}

Esta etapa tem por objetivo calcular os indicadores da mobilidade do TUC, devendo-se adotar como base para a seleção dos indicadores o conjunto proposto na Seção 3 (Tabela 2). Nesta etapa, são realizadas a atribuição do peso, mensuração e normalização dos indicadores selecionados.

\section{Definição dos pesos dos indicadores}

A definição dos pesos do índice deve ser realizada em duas etapas: (i) criação de um questionário para avaliação par a par dos indicadores e subindicadores; e (ii) quantificação dos pesos dos indicadores. A análise hierárquica de comparação par a par se baseia no método AHP- Analytic Hierarchy Process. Para facilitar o processo, utilizou-se o AHP simplificado, denominado SPC (Silva \& Silva, 2009). Optou-se por esta metodologia devido à facilidade de avaliação por parte do avaliador. A partir das respostas obtidas em cada questionário, são calculados os pesos individuais dos indicadores e subindicadores conforme o processo de análise hierárquica AHP (Saaty, 1977).

\section{Medição dos subindicadores e normalização}

Os subindicadores e indicadores possuem dimensões diferentes, entre quantitativos e qualitativos. Logo, devem ser normalizados para ficar em uma determinada escala, de maneira a garantir a coerência do resultado final. Para o índice proposto, optou-se pela escala de 0 a 1, havendo a possibilidade de este valor ser negativo conforme o sinal atribuído ao indicador (indicando se a medida não é favorável a mobilidade). A Tabela 3 apresenta o processo de normalização de cada subindicador para cada grupo de indicadores. Por sua vez, a Tabela 4 apresenta a influência de cada subindicador para o índice. 
Tabela 3 - Processo de normalização dos subindicadores

(Continua)

\begin{tabular}{|c|c|c|}
\hline Indicador & Subindicador & Como normalizar \\
\hline \multirow[t]{9}{*}{$\begin{array}{l}\text { Transporte } \\
\text { motorizado }\end{array}$} & $\begin{array}{l}\text { Baias ao longo da via } \\
\text { (segmento analisado) }\end{array}$ & $\begin{array}{l}\text {-Valor } 1 \text { para a presença de baias específicas para operações de carga e } \\
\text { descarga; }\end{array}$ \\
\hline & Condições dos pavimentos & $\begin{array}{c}V_{\text {cond.pavimento }}=(\text { Extensão do pavimento regular)/(Extensão total do trecho } \\
\text { analisado) }\end{array}$ \\
\hline & $\begin{array}{l}\text { Esquinas com ângulos } \\
\text { adequados } \\
\text { Inclinação da via }\end{array}$ & $\begin{array}{l}\text { Deve-se admitir valor de } 0 \text { para ângulos inferiores a } 90 \text { graus e } 1 \text { para esquinas } \\
\text { que possuam ângulo igual a } 90 \text { graus ou superior. } \\
\text { Deve-se admitir como valor ideal (valor } 1) \text { para uma inclinação menor ou igual } \\
\text { a 3\%, desta forma para determinar o valor dentro da escala (0-1) para outras } \\
\text { inclinações deve-se empregar a seguinte equação: } \\
\qquad \begin{array}{l}V_{\text {inc.via }}\left(0,03-V_{\text {inc.via }} / V_{\text {inc.via }}\right. \\
\text { Determinar a largura da via ideal e largura mínima para a via em análise: }\end{array}\end{array}$ \\
\hline & & $\begin{array}{l}\text { Vlarg.ideal da via=número de faixas } x \text { largura recomendada da faixa de rolamento } \\
\text { Vlarg.míno da via=número de faixas } x \text { largura mínima da faixa de rolamento } \\
\qquad(3,00 \mathrm{~m}) \\
\text { Comparação dos valores }\end{array}$ \\
\hline & & $\begin{array}{l}\text { Vlarg.da via em análise } \geq V_{\text {larg.ideal da via, atribui valor } 1} \\
V_{\text {larg.da via em análise }} \leq V_{\text {larg.ideal da via, verificar condições: }}\end{array}$ \\
\hline & & 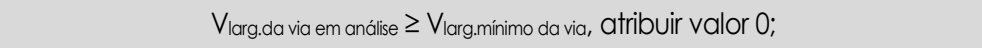 \\
\hline & & $\begin{aligned} V_{\text {larg.ideal da via }} \leq V_{\text {larg.da via em análise }} & \geq V_{\text {larg.mínimo da via, deve-se realizar a interpolação }} \\
& \text { entre os valores. }\end{aligned}$ \\
\hline & Número de faixas de & -Mão única com 1 faixa, considerar valor 0 ; \\
\hline & rolan & $\begin{array}{l}\text {-Mão única com } 2 \text { ou mais faixas, considerar valor 1; } \\
\text {-Mão dupla com } 1 \text { faixa, considerar valor } 0 \text {; } \\
\text {-Mão dupla com } 2 \text { ou mais faixas, considerar valor } 1 \text {; }\end{array}$ \\
\hline \multirow[t]{4}{*}{$\begin{array}{l}\text { Transporte não } \\
\text { motorizado }\end{array}$} & $\begin{array}{l}\text { Número de baias dentro de } \\
500 \mathrm{~m} \text { do PGV }\end{array}$ & 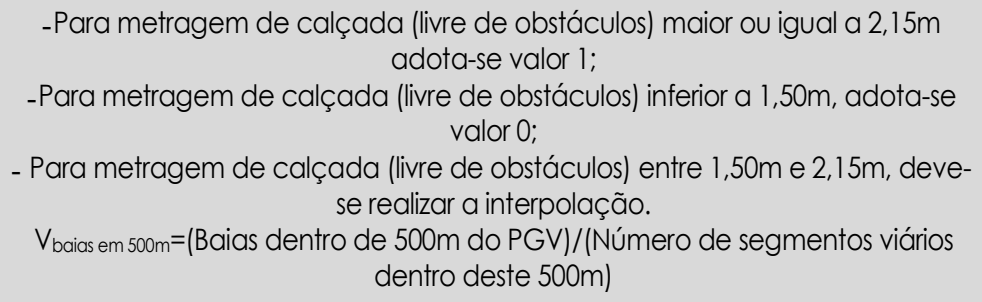 \\
\hline & Obstrução nas calçadas & $V_{\text {obst.calçada }}=($ Extensão das obstruções)/(Extensão total do trecho analisado) \\
\hline & Rampas entre calçadas e via & $\begin{array}{l}\text { Desta forma deve-se admitir um valor máximo de } 1 \text { para a região com } \\
\text { presença de rampas entre calçadas e via, e valor } 0 \text { para regiões sem rampas. }\end{array}$ \\
\hline & $\begin{array}{l}\text { Regularidade da } \\
\text { pavimentação da calçada }\end{array}$ & $\begin{array}{c}V_{\text {cond.pav.calçada }}=(\text { Extensão do pavimento regular }) /(\text { Extensão total do trecho } \\
\text { analisado) }\end{array}$ \\
\hline Uso do solo & Densidade comercial & $\begin{array}{c}V_{\text {dens.comercial }}=(\Sigma(\text { extensão do empreendimento comercial })) /(\text { metros do } \\
\text { segmento viário })\end{array}$ \\
\hline
\end{tabular}


(Conclusão)

\begin{tabular}{|c|c|}
\hline Densidade residencial & $\begin{array}{c}V_{\text {dens.residencial }}=(\Sigma(\text { extensão do empreendimento residencial })) /(\text { metros do } \\
\text { segmento viário })\end{array}$ \\
\hline \multirow{4}{*}{$\begin{array}{l}\text { Distância entre áreas de } \\
\text { comercio e centros de } \\
\text { distribuição }\end{array}$} & $V_{\text {dist.área comercial e centro de distr }}=(A-B) / A$ \\
\hline & Onde: \\
\hline & A - distância do comércio até o limite municipal $(\mathrm{km})$; \\
\hline & B - distância do comércio até o centro de distribuição (km). \\
\hline $\begin{array}{c}\text { Empreendimentos com } \\
\text { estacionamentos exclusivos } \\
\text { para carga }\end{array}$ & $\begin{array}{l}\text { Vemp.estc.exc.carga }=\text { (Número de empreendimentos com estacionamento exclusivo } \\
\text { para carga no segmento)/(Total empreendimentos no segmento) }\end{array}$ \\
\hline $\begin{array}{l}\text { PGV com acesso exclusive } \\
\text { para carga }\end{array}$ & $\begin{array}{c}\text { VPGV acesso carga }=\text { (Número de PGVs com acesso exclusivo para carga no } \\
\text { segmento)/(Total PGV no segmento) }\end{array}$ \\
\hline Transbordo em periferia & $\begin{array}{l}\text { Deve-se considerar valor máximo } 1 \text { para a existência de área de transbordo } \\
\text { em periferia e/ou regulamentação e } 0 \text { para a falta. }\end{array}$ \\
\hline
\end{tabular}

\section{Gestão do tráfego Fiscalização eletrônica de acesso e baias \\ Faixas de rolamento reversíveis para estacionamento e circulação \\ Permissão de trânsito em faixa de ônibus. \\ Sistema de informações do trânsito}

Transporte público compartilhado para carga Taxas de estacionamento da baia

\section{Condições de acesso}

\section{Classificação de zona de} carga

Estabelecimento de densidade mínima de ocupação do veículo

Monopolização das entregas

Pedágio urbano

Reserva eletrônica de vagas de carga e descarga
Deve-se admitir um valor máximo 1 para a região com presença de câmeras ao longo do segmento em análise e valor mínimo igual a 0 para onde não há.

Considera-se um valor máximo de 1 para segmento onde existe faixas reversíveis e valor 0 para segmento em que não exista faixa reversível.

Considera-se um valor de 0 para a inexistência de faixa reversivel e 1 para a existência.

Deve-se admitir um valor máximo 1 para o segmento em cuja via há presença de sistemas de informação, e valor igual a 0 para regiões sem a presença de sistemas de informações no segmento.

\section{Considera-se o uso do transporte público para transporte cargas, deve-se} admitir valor igual a 1 e 0 para o não emprego.

Deve-se admitir um valor máximo 1 para a região com presença de taxas de estacionamento nas baias independente do tipo de baia ou estacionamento para carga e descarga.

Considera-se valor 1 para placas que indiquem o horário de circulação ou de estacionamento para veículos de carga, 0,5 para a presença de placas que indiquem o limite de peso, altura ou volume do veículo de carga, valor e valor 0 para a inexistência total de placas indicativas.

Considera-se valor máximo de 1 para a situação favorável e 0 para a inexistência total de qualquer consideração quanto ao estabelecimento de densidade mínima de ocupação do veículo de carga para adentrar o centro urbano

Considerar valor de 1 para o caso de existir monopolização das entregas em mesmos dias, valor 0,5 para fornecedores iguais porém a entrega não é em mesmo dia, valor de 0,25 para locais que há concentração de comércios de mesma similaridade possuindo assim potencial para entregas monopolizadas e 0 para que não exista nenhuma das situações apresentadas.

Deve-se admitir um valor máximo 1 para a região com presença de pedágio urbano, e valor de 0 para regiões sem a presença de pedágios.

Deve-se considerar valor de 1 para situação de existência de reserva eletrônica de vaga e valor 0 para caso não exista reserva eletrônica de vagas

Fonte: Elaborada pelos autores. 
Tabela 4 - Influência de cada subindicador no índice

(Continua)

\begin{tabular}{|c|c|c|c|}
\hline Indicadores & Subindicadores & Influência & Resultado da influência \\
\hline \multirow[t]{5}{*}{$\begin{array}{l}\text { Condições de } \\
\text { acesso }\end{array}$} & Monopolização das entregas & + & $\begin{array}{l}\text { Quanto maior for o incentivo para os comércios efetuarem a } \\
\text { monopolização de entregas, menos veículos de carga irão circular nas }\end{array}$ \\
\hline & $\begin{array}{l}\text { Reserva eletrônica de vagas } \\
\text { de carga e descarga }\end{array}$ & + & $\begin{array}{l}\text { ruas. } \\
\text { A reserva eletrônica de vaga estimulará as entregas a serem } \\
\text { programadas, diminuindo a circulação de veículos na rua e a procura } \\
\text { de vagas. }\end{array}$ \\
\hline & $\begin{array}{l}\text { Classificação de zona de } \\
\text { carga }\end{array}$ & + & $\begin{array}{c}\text { A classificação das vias para a zona de carga quanto a horários para } \\
\text { circulação na via, limite de peso etc. Diminui o número de veículos em } \\
\text { determinada área }\end{array}$ \\
\hline & $\begin{array}{l}\text { Estabelecimento de } \\
\text { densidade mínima de } \\
\text { ocupação do veículo }\end{array}$ & + & $\begin{array}{l}\text { O estabelecimento da densidade mínima visa a diminuição do fluxo de } \\
\text { veículos de carga em determinada área }\end{array}$ \\
\hline & Pedágio urbano & + & $\begin{array}{l}\text { O pedágio urbano diminui o fluxo de veículos de carga em } \\
\text { determinada área, estimula monopolização de entregas e } \\
\text { entregas/coletas programadas }\end{array}$ \\
\hline \multirow[t]{6}{*}{$\begin{array}{l}\text { Gestão do } \\
\text { tráfego }\end{array}$} & $\begin{array}{l}\text { Fiscalização eletrônica de } \\
\text { acesso e baias }\end{array}$ & + & $\begin{array}{l}\text { A fiscalização eletrônica evita que outros veículos ocupem as vagas de } \\
\text { veículos de carga, além de limitar o tempo dentro delas, }\end{array}$ \\
\hline & $\begin{array}{l}\text { Faixas de rolamento } \\
\text { reversíveis ä estacionamento } \\
\text { e circulação }\end{array}$ & + & $\begin{array}{l}\text { Estabelecer horário para reverter faixa de rolamento em faixa de } \\
\text { estacionamento, facilita as operações de carga e descarga }\end{array}$ \\
\hline & $\begin{array}{l}\text { Permissão de trânsito em } \\
\quad \text { faixa de ônibus }\end{array}$ & + & $\begin{array}{l}\text { A permissão de trânsito em faixa de ônibus em determinados horários } \\
\text { ajuda escoar o fluxo }\end{array}$ \\
\hline & $\begin{array}{l}\text { Sistema de informações de } \\
\text { trânsito }\end{array}$ & + & $\begin{array}{l}\text { O sistema de informações facilita a escolha de rotas que estejam livres } \\
\text { para circulação }\end{array}$ \\
\hline & $\begin{array}{l}\text { Transporte público } \\
\text { compartilhado para carga }\end{array}$ & + & $\begin{array}{l}\text { O transporte público compartilhado para a carga, facilita o } \\
\text { escoamento das mercadorias }\end{array}$ \\
\hline & $\begin{array}{l}\text { Taxas de estacionamento } \\
\text { das baias }\end{array}$ & + & $\begin{array}{c}\text { A cobrança de taxas para estacionamento evita que veículos ocupem } \\
\text { as vagas sem necessidade }\end{array}$ \\
\hline \multirow[t]{6}{*}{ Uso do solo } & Densidade comercial & - & $\begin{array}{c}\text { Quanto maior a densidade comercial, mais será necessária a } \\
\text { implementação de boas medidas para receber as mercadorias } \\
\text { transportadas naquela área }\end{array}$ \\
\hline & Densidade residencial & + & $\begin{array}{l}\text { A densidade residencial em proporção à comercial contribui para o } \\
\text { escoamento das mercadorias por outros meios não motorizados }\end{array}$ \\
\hline & $\begin{array}{l}\text { Distância entre área de } \\
\text { comércio e centro de } \\
\text { distribuição }\end{array}$ & - & $\begin{array}{c}\text { Quanto maior a distância entre o comércio e a área destinada a } \\
\text { centros de distribuição de mercadorias, maior é a distância a ser } \\
\text { percorrida dentro da cidade, contribuindo para a redução da } \\
\text { mobilidade em diversas áreas da cidade }\end{array}$ \\
\hline & $\begin{array}{l}\text { Empreendimentos com } \\
\text { estacionamento exclusivo } \\
\text { para carga }\end{array}$ & + & $\begin{array}{l}\text { A determinação de que empreendimentos tenham estacionamentos } \\
\text { para facilitar as operações de carga e descarga }\end{array}$ \\
\hline & $\begin{array}{l}\text { PGV com acesso exclusivo } \\
\text { para carga }\end{array}$ & + & $\begin{array}{l}\text { A determinação de que empreendimentos tenham acessos para } \\
\text { carga facilita as operações de carga e descarga }\end{array}$ \\
\hline & Transbordo em periferia & + & $\begin{array}{c}\text { A estipulação de transbordo em periferia contribui para a distribuição } \\
\text { de cargas para outros veículos (menores) e até outras formas de } \\
\text { distribuição. }\end{array}$ \\
\hline \multirow[t]{7}{*}{$\begin{array}{l}\text { Transporte } \\
\text { motorizado }\end{array}$} & Baias ao longo da via & + & $\begin{array}{l}\text { O maior o número de baias ao longo da via, possibilitará que as } \\
\text { operações de carga e descarga sejam de forma compartilhada } \\
\text { (metade motorizada metade a propulsão humana) }\end{array}$ \\
\hline & Baias em ruas de serviço & + & $\begin{array}{l}\text { Baias em ruas de serviço não atrapalham o fluxo de veículos em ruas } \\
\text { principais (onde há maior circulação de pessoas e automotores) }\end{array}$ \\
\hline & Condições dos pavimentos & + & $\begin{array}{l}\text { A condição dos pavimentos da via facilita o deslocamento de veículos } \\
\text { de carga }\end{array}$ \\
\hline & $\begin{array}{l}\text { Esquinas com ângulos } \\
\text { adequados }\end{array}$ & + & Esquinas que possuem ângulos mais abertos \\
\hline & Inclinação da via & + & Inclinação suave facilita o deslocamento de veículos de carga \\
\hline & Largura da via & + & $\begin{array}{l}\text { A largura adequada da via facilita o deslocamento de veículos de } \\
\text { carga }\end{array}$ \\
\hline & $\begin{array}{l}\text { Número de faixas de } \\
\text { rolamento por sentido }\end{array}$ & + & $\begin{array}{l}\text { Quanto mais números de faixas por sentido, menor será a redução da } \\
\qquad \text { velocidade do fluxo na via }\end{array}$ \\
\hline $\begin{array}{l}\text { Transporte não } \\
\text { motorizado }\end{array}$ & Largura livre da calçada & + & $\begin{array}{l}\text { A largura da calçada influencia as entregas a pé ou por outros } \\
\text { mecanismos, a propulsão humana }\end{array}$ \\
\hline
\end{tabular}


(Conclusão)

Número de baias em um raio de $500 \mathrm{~m}$ do PGV

Obstrução nas calçadas

Rampas entre calçada e via

Regularidade da pavimentação da calçada
+ O maior número de baias dentro de 500m de um PGV facilita a carga/descarga do veículo.

Quanto maior a obstrução das calçadas, menor será o estímulo, as entregas a pé ou outras formas não motorizadas

A existência de rampas entre as calçadas e via facilita entregas de modo não motorizado

A regularidade da pavimentação facilita entregas de modo não motorizado

Fonte: Elaborada pelos autores.

\section{Ełapa 3: Determinação do índice de mobilidade para o transporte urbano de carga}

A definição do IMTUC corresponde à associação de pesos e valores (medições em campo). A base para a estrutura proposta para determinação do IMTUC foram os estudos de Campos et al. (2005) e Costa (2003), que propõem índices de Modalidade para transporte de passageiros. Desta forma, para definição do IMTUC, propõe-se a formulação representada pela Equação 1.

IMTUC $=\sum_{1=i}^{n} W_{i} \cdot \sum_{J=1}^{m} \alpha W_{j} \cdot V_{j}$

$w_{i}$ - Peso relativo de indicador

$\alpha$ - tem valor 1 ou -1 , se a variável contribui de forma positiva ou negativa

$W_{j}$ - Peso relativo do subindicador

$V_{j}$ - Valor medido em campo

A escala escolhida para variação do valor do índice é entre 0 ( zero) e 1,0 (um), onde resultados mais próximos de 0 indicam que a região não é mais ideal para acréscimo de comércio e ainda precisa de melhorias em relação a alguns indicadores. Por sua vez, um valor de índice próximo de 1 indica que aquela área é capaz de receber comércio de maneira a sustentar a movimentação que é gerada pela atividade.

No processo desenvolvido, o IMTUC é calculado para cada segmento de via coletora e ou arterial na região analisada. Após este cálculo, uma média dos valores dos segmentos define o IMTUC da via e uma média dos valores destas vias o IMTUC da região.

A análise de cada indicador que compõe o IMTUC e seus subindicadores pode apontar as principais carências da área analisada. Portanto, as ações relacionadas a estes indicadores devem ser avaliadas, de modo a melhorar a mobilidade para carga urbana e, por consequência, a mobilidade urbana geral da região. Deste modo, contribuem para reduzir os impactos da circulação de veículos de carga e, consequentemente, mitigar as externalidades do TUC sobre o meio-ambiente e sobre a qualidade de vida da população local.

\section{Aplicação do índice de mobilidade para TUC}

Para aplicação do índice de mobilidade para TUC, seguiu-se a estrutura do procedimento proposto na Seção 4. Os resultados são apresentados a seguir.

\section{Ełapa 1: Determinação da área de estudo}

A cidade de Niterói (RJ) foi escolhida para aplicação do índice IMTUC. A escolha foi motivada pelo fato de ser uma cidade de porte médio com áreas de significativa concentração de comércio e, consequentemente, grande fluxo de veículos de carga. A cidade possui uma área de $134 \mathrm{~km}^{2}$ e aproximadamente 500.000 habitantes e é dividida em 51 bairros, sendo o setor terciário a base de sua economia. Os bairros de Niterói que concentram maior quantidade de comércio são Icaraí e Centro. Porém, o comércio no bairro Icaraí é mais 
voltado para a área de vestuário e clinicas de estéticas, havendo maior diversidade no Centro. Portanto, definiu-se a região central como área crítica para o estudo. Em seguida, foram selecionadas 22 ruas na área de estudo, entre elas transversais e longitudinais, criando-se uma malha com 41 quadras para análise, conforme Figura 1.
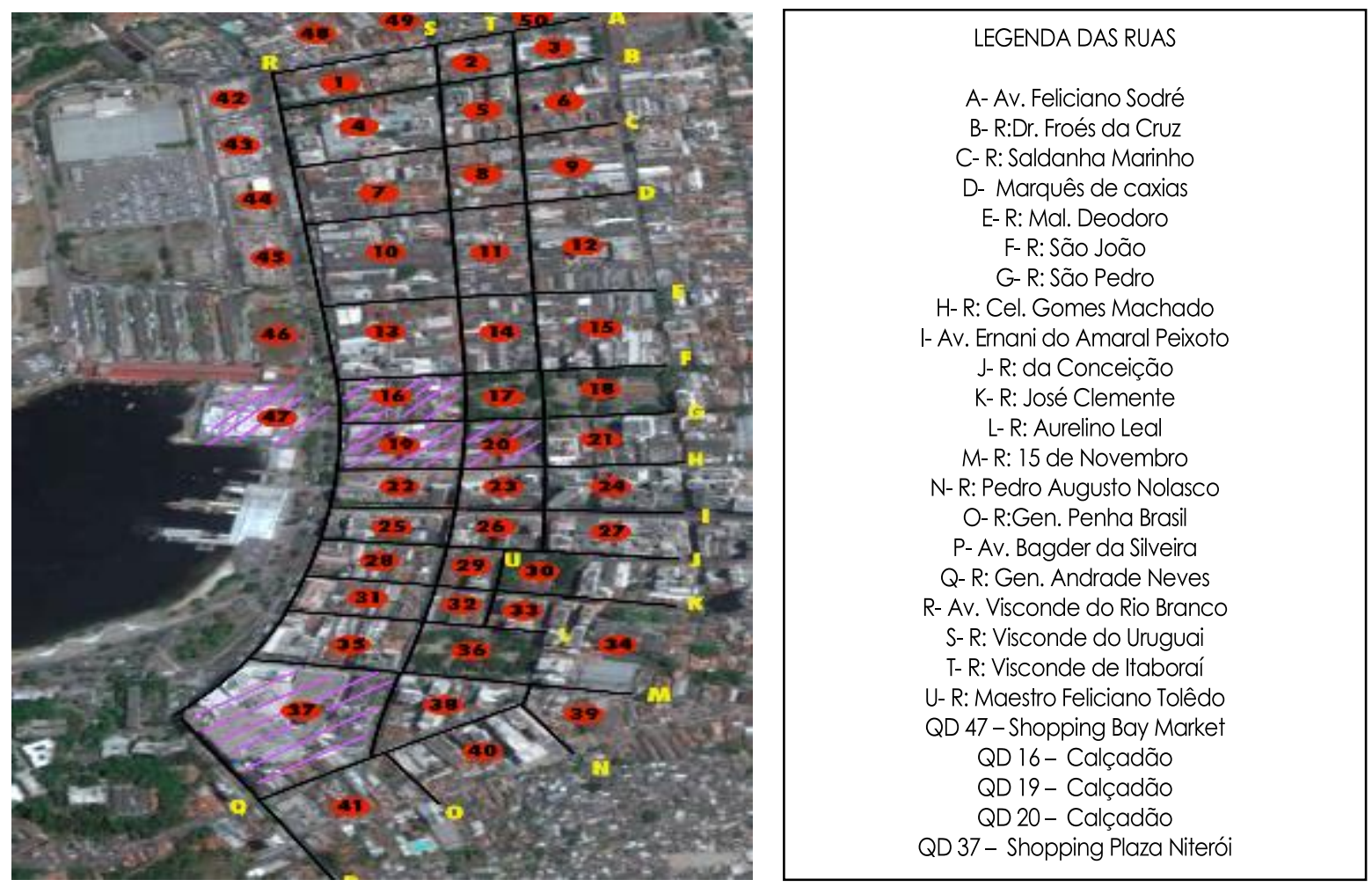

Figura 1 - Área analisada. Fonte: Adaptado de GoogleMaps (Acesso em fevereiro, 2016).

\section{Etapa 2: Medição e quantificação dos indicadores na área de estudo}

Os pesos dos indicadores foram obtidos por meio do método SPC. Para tanto, foi elaborado um questionário respondido por um grupo de 11 especialistas da área de transporte de carga urbana. Os especialistas possuem doutorado em Engenharia de Transportes e mais de 10 anos de experiência em projetos nas mais diversas regiões do país. 0 resultado da medição e normalização dos pesos dos indicadores e subindicadores é apresentado na Tabela 5. 
Tabela 5 - Pesos dos indicadores e subindicadores obtidos pelo SPC

\begin{tabular}{|c|c|c|c|}
\hline Indicador & Peso & Sub-indicadores & Peso \\
\hline \multirow{7}{*}{$\begin{array}{l}\text { Transporte } \\
\text { Motorizado }\end{array}$} & \multirow{7}{*}{0,249} & Baias de carga e descarga ao longo da via & 0,148 \\
\hline & & Baias de carga em ruas de serviço & 0,176 \\
\hline & & Condições dos pavimentos & 0,116 \\
\hline & & Esquinas com ângulos adequados & 0,083 \\
\hline & & Inclinação da via & 0,055 \\
\hline & & Largura das vias & 0,270 \\
\hline & & Número de faixas de rolamento por sentido & 0,152 \\
\hline \multirow{5}{*}{$\begin{array}{l}\text { Transporte NAO } \\
\text { Motorizado }\end{array}$} & \multirow{5}{*}{0,096} & Largura livre da calçada & 0,239 \\
\hline & & Baias com distancia inferior a 500m dos PGVs & 0,217 \\
\hline & & Obstruções nas calçadas & 0,250 \\
\hline & & Rampas entre calçada e via & 0,149 \\
\hline & & Regularidade da pavimentação das calçadas & 0,144 \\
\hline \multirow{6}{*}{ Uso do solo } & \multirow{6}{*}{0,339} & Densidade comercial & 0,321 \\
\hline & & Densidade residencial & 0,068 \\
\hline & & Distância entre áreas de comercio e centros de distribuição & 0,235 \\
\hline & & Empreendimentos com estacionamento exclusive para carga & 0,140 \\
\hline & & PGV com acesso exclusive para carga & 0,174 \\
\hline & & Transbordo em periferia & 0,062 \\
\hline \multirow{6}{*}{$\begin{array}{l}\text { Gestão do } \\
\text { tráfego }\end{array}$} & \multirow{6}{*}{0,180} & Fiscalização eletrônica de acessos e baias & 0,219 \\
\hline & & $\begin{array}{l}\text { Faixas de rolamento reversíveis para estacionamento e } \\
\qquad \text { circulação }\end{array}$ & 0,192 \\
\hline & & Permissão de trânsito em faixa de ônibus & 0,107 \\
\hline & & Sistema de informações do trânsito & 0,263 \\
\hline & & Transporte público compartilhado para carga & 0,094 \\
\hline & & Taxas de estacionamento da baia & 0,125 \\
\hline \multirow{5}{*}{$\begin{array}{l}\text { Condições de } \\
\text { acesso }\end{array}$} & \multirow{5}{*}{0,136} & Monopolização das entregas & 0,081 \\
\hline & & Reserva eletrônica de vagas de carga e descarga & 0,272 \\
\hline & & Classificação de zonas de carga & 0,292 \\
\hline & & $\begin{array}{c}\text { Estabelecimento de densidade mínima de ocupação do } \\
\text { veículo }\end{array}$ & 0,217 \\
\hline & & Pedágio urbano & 0,138 \\
\hline
\end{tabular}

Fonte: Elaborada pelos autores.

Ełapa 3: Determinação do índice de mobilidade para o transporte urbano de carga

Por meio dos pesos dos indicadores e subindicadores e seus valores normalizados dentro da escala, calcula-se o índice. Como a área analisada foi separada em malhas, foi possível calcular os índices por segmento, por via e para a região estudada.

- Índice por segmento (IMTUCsegmento): é o valor de cada subindicador para cada segmento analisado. Os valores observados são normalizados (na escala de 0 a 1 ) e então multiplicados por seus respectivos pesos e de seus indicadores, obtendo-se assim o valor final do índice por segmento.

- Índice por via (IMTUCvia): é obtido pela média dos valores do índice dos segmentos analisados pertencentes àquela via;

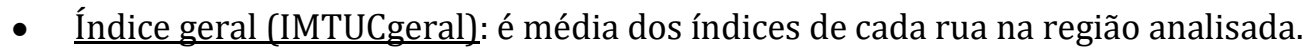


Os valores do índice por segmento (IMTUCsegmento) obtidos para a região central de Niterói são baixos, variando entre 0,109 e 0,391. A Figura 2 apresenta os valores do índice por segmento (IMTUCsegmento) para as ruas A,B,C,D, R (até quadras 44-7), S (até quadras 7-8) e T (até quadras 8-9).

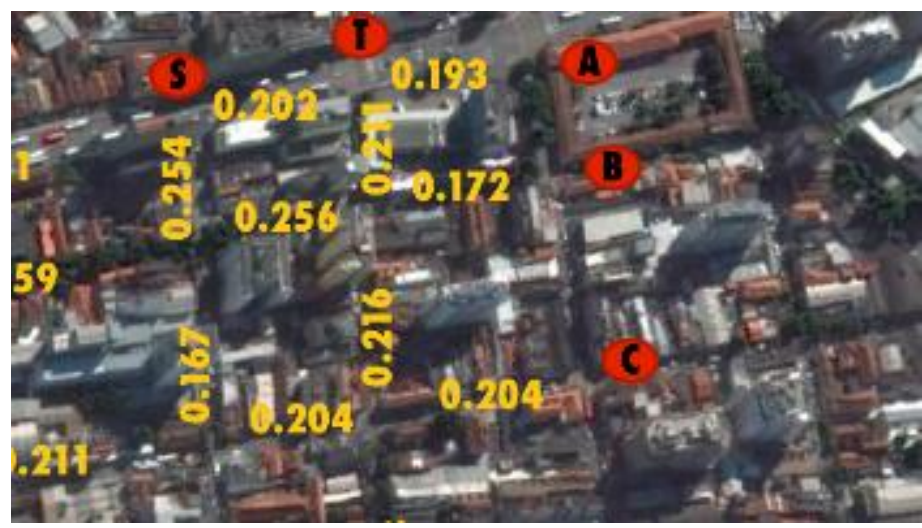

Figura 2 - Valores de IMTUCsegmento pertencentes às vias A,B, C e D. Fonte: Elaborada pelos autores.

A Tabela 6 apresenta os resultados do IMTUC para as vias. Nota-se que a Rua Pedro Augusto Nolasco (Rua N) apresenta o maior IMTUCvia (0.352). Apesar de estar próximo a um PVG, esta via não é uma rua de muito comércio. 0 menor índice calculado é o da Rua Maestro Feliciano Toledo (Rua U), cujo IMTUCvia corresponde a 0,140. Esta via em toda sua extensão possui comércio, porém sem condições adequadas para isto.

Tabela 6 - Valores de IMTUCvia

\begin{tabular}{lcc}
\hline & Índice por via & \\
\hline Rua A & Av. Feliciano Sodré & 0,286 \\
Rua B & Dr. Fróes da Cruz & 0,249 \\
Rua C & Saldanha Marinho & 0,262 \\
Rua D & Marquês de Caxias & 0,296 \\
Rua E & Mal Deodoro & 0,284 \\
Rua F & São João & 0,222 \\
Rua G & Cel. Gomes Machado & 0,160 \\
Rua H & São Pedro & 0,227 \\
Rual & Av. Ernani do Amaral Peixoto & 0,298 \\
Rua J & Rua da Conceição & 0,203 \\
Rua K & José Clemente & 0,169 \\
Rua L & Aurelino Leal & 0,284 \\
Rua M & 16 de Novembro & 0,253 \\
Rua N & Pedro Augusto Nolasco & 0,352 \\
Rua O & Tv. Gen Penha Brasil & 0,281 \\
Rua P & Av. Bagder da Silveira & 0,271 \\
Rua Q & Gen. Andrade Neves & 0,347 \\
Rua R & Av. Visconde do Rio Branco & 0,184 \\
Rua S & Visconde do Uruguai & 0,171 \\
Rua T & Visconde de ltaboraí & 0,239 \\
Rua U & Maestro Felicíssimo Toledo & 0,140 \\
\hline
\end{tabular}

Fonte: Elaborada pelos autores.

0 índice geral do IMTUC para a região analisada equivale a 0,2465 . Se considerarmos uma escala de valores de mobilidade em que: de 0 a 0,25 é muito baixa, $>0,25$ a 0,50 baixa, $>0,50$ a 0,75 boa e $>0,75$ a 1,0 como muito boa, pode-se concluir que a região do bairro Centro de Niterói não está apta a receber novos 
empreendimentos comerciais, pois tem um índice de mobilidade baixo, a não ser que sejam aplicadas medidas para melhorar os valores dos indicadores obtidos em campo.

\section{Análise dos resultados encontrados}

O procedimento proposto permite o cálculo de índices de mobilidade para o transporte urbano de carga para cada segmento de via, para a via e para a região estudada. Ao analisar os valores de IMTUC por segmento obtidos para a região central de Niterói, nota-se que são valores inferiores a 0.30 , que é considerado um índice baixo (valor entre 0,25 e 0,5) dentro da escala de 0 a 1 . Este resultado, de fato, reflete as condições de trânsito encontradas na região. Niterói é apontada, em pesquisa realizada pela 99, empresa brasileira de mobilidade urbana por aplicativo de celular, como a cidade com a pior avaliação em ranking sobre a situação do trânsito em 30 cidades do país (Pfeffer, 2018).

Para melhor compreensão dos resultados apresentados na seção 5, é necessário avaliar os valores dos indicadores obtidos para cada segmento de via. Ao se comparar os valores obtidos para cada subindicador ou ainda para cada indicador, pode-se identificar aqueles que apresentam boas condições, bem como aqueles que necessitam de intervenções e medidas para melhorar o seu desempenho, apontando ainda as vias prioritárias para receber tais serviços (ou seja, aquelas com piores notas). Desta análise para a região central de Niterói, pode-se concluir que:

- O indicador transporte motorizado é o que apresenta o maior valor em quase todos os segmentos analisados. Isto demonstra que o local de análise tem maior propensão em possuir movimentações de carga por meios motorizados, visto que as condições encontradas são mais propícias (oferta de baias para operação de carga e descarga, boas inclinações das vias, condições de pavimentos favoráveis ao trânsito de veículos);

- Para o indicador de transporte não motorizado, observou-se que o subindicador de maior destaque é a largura efetiva da calçada, com boas condições na maioria dos casos (visível nos segmentos das principais vias Visconde do Rio Branco e Av. Amaral Peixoto);

- 0 indicador de gestão do tráfego foi o que obteve os piores resultados, com mais da metade dos subindicadores apresentando valores nulos devido à ausência de: fiscalização eletrônica das baias ou de acessos, sistemas de informação de trânsito em tempo real, compartilhamento do transporte público com o transporte de carga e permissão de trânsito de veículos de carga em faixas de ônibus (mesmo em horários fora de pico). Existe, na região, apenas a cobrança de taxas de estacionamento, que é considerada uma medida positiva, pois estimula que as entregas ocorram de forma programada, evitando desperdício de tempo no estacionamento e circulação desnecessária nas vias, causando lentidão ou obstrução nas vias.

- Também não foram obtidos bons resultados para o indicador de restrição de acesso nos segmentos analisados. Isto se dá pela ausência, na região, dos seguintes subindicadores: pedágio urbano, estabelecimento de densidade mínima de ocupação dos veículos e reserva eletrônica das vagas de carga e descarga. Foi observada apenas a classificação de zona de carga (estabelecimento de horários de circulação, peso e altura dos veículos) e a monopolização das entregas (entregas feitas por mesmos fornecedores).

Desta forma, os baixos valores para o índice IMTUC para os segmentos de via na região estudada devemse aos valores baixos obtidos com os indicadores: transporte motorizado, transporte não motorizado, uso do solo, gestão do tráfego e restrições de acesso. 0 indicador transporte motorizado, apesar de não ser próximo de 1 , apresenta valor mais elevado.

Os baixos valores para o indicador transporte não motorizados indicam a necessidade de melhoria dos pavimentos das calçadas e suas larguras, além de evitar obstruções por ambulantes ou por lojas, causadas pela exposição de produtos na calçada. Porém, os resultados mais baixos foram obtidos para os indicadores de gestão do tráfego juntamente com a restrição de acesso. Isso se deve à falta de cobrança de taxas especiais para circulação de mercadorias dentro das zonas urbanas (por meio de pedágios, taxas em baias de carga e descarga), restrições de circulação de horário ou para operações de carga e descarga, além de incentivo à monopolização de entregas. Deste modo, estes resultados indicam as medidas cuja implantação deve ser 
considerada pelos gestores públicos de modo a melhorar as condições de tráfico e a mobilidade referente ao TUC na região central de Niterói.

Como resultado para índice IMTUCvias, a via de maior valor $(0,352)$ é a Rua Pedro Augusto Nolasco, que, apesar de não possuir tanto comércio, é próxima a um PGV. Este resultado ainda está na faixa considerada como baixa mobilidade, refletindo assim o impacto que um PGV pode gerar na circulação devido à atratividade tanto de pessoas quanto de carga.

Enfim, o índice geral IMTUCgeral para a região analisada equivale de 0, 2465. Este valor indica que esta área não apresenta boas condições para a circulação de carga, não estando apta a receber novos empreendimentos comerciais que gerem fluxos de mercadorias em intensidade. Ao analisar a realidade do trânsito na região, verifica-se que os valores obtidos para IMTUC de fato correspondem ao resultado do índice. Em outras palavras, os baixos índices podem ser comprovados quando verificados visualmente, notando-se, por exemplo, vários veículos de carga em circulação e parados em vias que não podem estar. Tais condições influenciam a mobilidade geral da região (mobilidade de veículos individuais, coletivos e pedestres).

\section{Considerações finais}

O objetivo desta pesquisa consistiu em propor um procedimento para determinação de um índice de mobilidade para o TUC. É importante destacar que procedimentos com estruturas similares já haviam sido propostos na literatura (Costa, 2008, Banister et al., 2000, Campos \& Ramos, 2005; Campos, 2006; Gayda et al., 2005; Lautso et al., 2004, Minken et al. 2001) para avaliar a mobilidade urbana, porém por meio de indicadores relacionados à operação e à infraestrutura de transporte urbano de passageiros. Neste trabalho, é apresentada uma primeira proposta para a estimativa de um índice que represente o nível de mobilidade para o TUC, que pode vir a ser trabalhada em futuras pesquisas.

O índice proposto é capaz de sinalizar se uma determinada área está apta a receber novos empreendimentos comerciais que gerem movimentação de carga em seu entorno. A importância do desenvolvimento desta pesquisa se dá pelo fato da constante expansão das cidades e consequente aumento da circulação de pessoas, veículos e cargas. Quando estes não são corretamente planejados afetam a mobilidade urbana por inteiro, criando vários problemas que afetam aspectos sociais, econômicos e ambientais da vida na cidade. Assim, o IMTUC pode ser auxiliar da administração pública ao tomar decisões sobre o planejamento do transporte urbano de carga, uma vez que permite identificar medidas a serem implantadas visando uma melhor circulação de veículos de carga e, consequentemente, um menor impacto na região.

Para definir este índice, foi desenvolvida uma revisão bibliográfica sobre as ações empregadas para mitigar os problemas gerados pelo TUC, a partir da qual foram levantadas 54 questões relacionadas a tais ações. Da análise destas ações, foram identificadas aquelas que estavam relacionadas com o poder público, gerando um conjunto de 29 subindicadores. Esses foram agrupados em cinco indicadores, conforme a categorização de Muñuzuri et al. (2005), e compõem o IMTUC. Além disso, desenvolveu-se uma pesquisa AHP para se obter pesos dos indicadores e subindicadores, de forma a incorporar o nível de importância de cada um na composição do índice.

0 procedimento proposto para cálculo do índice foi aplicado no centro da cidade de Niterói. Porém, os índices calculados apresentaram valores baixos (inferiores a 0,5), de modo que a área analisada não apresenta boas condições para a circulação de carga, não sendo recomendado que sejam acrescidos mais comércios na região. Assim, caso seja necessário implantar novas formas de comércio, é importante que sejam feitas intervenções a fim de melhorar a mobilidade na região, melhorando os sub indicadores de baixo valor.

Quando se avalia visualmente a realidade do trânsito na região, verifica-se que o valor baixo do IMTUC caracteriza as condições precárias de mobilidade observadas no transporte de carga na mesma. Portanto, caso seja necessário implantar novas formas de comércio, devem ser feitas intervenções para melhorar a mobilidade na região, aumentando assim os valores dos indicadores de cada IMTUC. Logo, devem ser revistos os subindicadores que apresentaram valores baixos. 
Enfim, destaca-se que o procedimento proposto pode ser aplicado em qualquer cidade, desde que se leve em conta, nos parâmetros de avaliação dos indicadores, valores e medidas já estabelecidos por normativas e leis da cidade em questão. Além disto, sugere-se que, para futuros estudos, seja desenvolvido, com base no índice proposto, um processo de análise de sensibilidade em relação ao quanto se ganha com as medidas e restrições aplicadas com foco no TUC. Também é importante estabelecer uma relação entre o fluxo de veículos e o índice para uma tomada de decisão quanto às medidas a serem implantadas na região.

\section{Referências}

Abdala, I. M. de R.; A. Pasqualetto. (2013). Índice de mobilidade urbana sustentável em Goiânia como ferramenta para políticas públicas. Caderno Metropolitano, 15(30), 490-511. Recuperado em 13 de outubro de 2014, de http://www.cadernosmetropole.net/download/cm_artigos/cm30_272.pdf

Agência Portuguesa do meio Ambiente. (2011). Critérios de Boa Prática na Selecção de Medidas de Mitigação e Programas de Monitorização: Primeira aproximação. Recuperado em 16 de abril de 2014, de https://www.iaia.org/publicdocuments/special-publications/Boa Pratica_de Monitorização.pdf

Ballantyne, E. E., Lindholm, M., \& Whiteing, A. (2013). A comparative study of urban freight transport planning: addressing stakeholder needs. Journal of transport geography, 32, 93-101.

Banco Mundial. (2015). World Development Indicators: Urbanization. Recuperado em 12 de outubro de 2015, de http://wdi.worldbank.org/table/3.12

Banister, D., Stead D.,Steen, P., Akerman, J., Dreborg, K., Nijikamp, P., Tappeser R. S. (2000). Targets for Sustainability Mobility, European Transport Policy and Sustainability (cap.8, p. 119). London: Spon Press.

Bestufs: Guia de Boas Práticas no Transporte Urbano de Mercadorias. Alemanha: Bestufs, (2013). Recuperado em 12 de outubro de 2015, de

http://webcache.googleusercontent.com/search?q=cache:tF8wg2YzDJkJ:www.bestufs.net/download/BESTUFS_II/goo d_practice/Portuguese_BESTUFS_Guide.pdf+\&cd=1\&hl=pt-BR\&ct=clnk\&gl=br

Betanzo-Quezada, E., \& Romero, J. A. (2010). An urban freight transport index. Procedia-Social and Behavioral Sciences, 2(3), 6312-6322.

Bozzo, R., Conca, A., \& Marangon, F. (2014). Decision support system for city logistics: literature review, and guidelines for an ex-ante model. Transportation Research Procedia, 3, 518-527.

Campos, V. B. G. \& Ramos, R. A. R. (2005). Proposta de índice de mobilidade sustentável para áreas urbanas. $2005 \mathrm{~b}$. Recuperado em 30 de outubro de 2015, de http://aquarius.ime.eb.br/ webde2/prof/vania/pubs/(22)INDICE.pdf

Campos, V. B. G. (2006). Uma visão da mobilidade urbana sustentável. Revista dos Transportes Públicos, 2, 99-106. Recuperado em 25 de março de 2015, de

http://aquarius.ime.eb.br/ webde2/prof/vania/pubs/(3)UMAVISAODAMOBILIDADE.pdf

C-Liege. (2010). Clean Last Mile Transport and Logistics Management for Smart and Efficient Local Governments in Europe. Roma: C-liege. Recuperado em 12 de novembro de 2015, de

http://webcache.googleusercontent.com/search?q=cache:lY2OTVpJCvcJ:www.c-liege.eu/fileadmin/Media/cliege.eu/Downloads/C-Liege_1_Brochure_Portugal.pdf+\&cd=1\&hl=pt-BR\&ct=clnk\&gl=br

Costa, M. S. (2003). Mobilidade Urbana Sustentável: Um Estudo Comparativo e as Bases de Um Sistema de Gestão para Brasil e Portugal. 2003. 196f. Dissertação (Mestrado em Engenharia de Transportes). Programa de Pós- Graduação em Engenharia de Transportes, Escola de Engenharia de São Carlos da Universidade de São Paulo, São Carlos.

Costa, M. S. (2008). Um Índice de Mobilidade Urbana Sustentável. Tese (Doutorado em Transportes). Universidade de São Paulo. Escola de Engenharia de São Carlos, São Carlos, São Paulo.

Crainic, T. G., Ricciardi, N. E. Storchi, G. (2004). "Advanced freight transportation systems for congested urban areas". Transportation Research Part C, 12, 119-137.

Domínguez, A., Holguín-Veras, J., Ibeas, A. \& Dell'olio, L. (2012) Receivers' response to new urban freight policies. Procedia - Social and Behavioral Sciences, 54, 886-896. 
Dutra, N. G. da S. (2004). O enfoque de "citylogistics" na distribuição urbana de encomendas. 2004. 229 f. Tese (Doutorado). Curso de Programa de Pós Graduação em Engenharia de Produção, Universidade Federal de Santa Catarina, Florianópolis.

Emberger, G. (2004). Plume - Planning and Urban Mobility in Europe: Synthes is Reporton Urban Freight Transport Measures: Plume. Recuperado em 20 de dezembro de 2014, de http://www.cabri-volga.org/DOC/EG4/PLUME.pdf

Gatta, V. \& Marcucci, E. (2014). Urban freight transport and policy changes: Improving decision makers' awareness via an agent-specific approach. Transport policy, 36, 248-252.

Gayda, S., Haag, G., Besussi, E., Lautso, K., Nol, C., Martino, A. (2005). The SCATTER Project - Sprawling Cities and Transport: From Evaluation to Recommendations. 2. União Européia.

Holguín-Veras, J. (2015). Improving Freight System Performance in Metropolitan Area: A Planning Guide. TRB’s National Cooperative Freight Research Program (NCFRP) Report 33. Washington, Dc, USA.

IMTT - Instituto Da Mobilidade E Dos Transportes Terrestres. (2011). Guia para a elaboração de planos de mobilidade e transportes. Lisboa: Imtt. Recuperado em 15 de julho de 2014, de http://www.conferenciamobilidade.imtt.pt/pacmob/guia_pmts/Guia_para_a_elaboracao_de_PMT_Marco_2011.pdf

Lagorio, A., Pinto, R., \& Golini, R. (2016). Research in urban logistics: a systematic literature review. International Journal of Physical Distribution \& Logistics Management, 46(10), 908-931.

Lautso, K. (2004). PROPOLIS - Planning and Research of Policies for Land Use and Transport for Increasing Urban Sustainability. Recuperado em 15 de outubro de 2015, de http://www.transportresearch.info/web/projects/project_details.cfm?ID=4385

Leonardi, J., Browne, M., Allen, J., Bohne, S., \& Ruesch, M. (2014). Best practice factory for freight transport in Europe: demonstrating how 'good'urban freight cases are improving business profit and public sectors benefits. Procedia-Social and behavioral sciences, 125, 84-98.

Lindhome, M. \& Behrends, S. (2012). Challenges in urban freight transport planning - a review in the Baltic Sea Region. Journal of Transport Geography, 22 , 129-136.

Lindholm, M. E., \& Blinge, M. (2014). Assessing knowledge and awareness of the sustainable urban freight transport among Swedish local authority policy planners. Transport policy, 32, 124-131.

Macharis, C., Melo, S. (2011). City Distribution and Urban Freight Transport: Multiple Perspectives. Edward Elgar Publisher, Cheltenham.

III Megacity Logistics Workshop, 3, 2015. Rio de Janeiro: Anpet, 2015. p. 1 - 7. Disponível em: <http://www.anpet.org.br/portal/images/noticias/iii_megacity_logistic/boas_praticas_e_desafios_iii_megacity_logistic .pdf>. Acesso em: 01 dez. 2015.

Minken, H.; Samstad, H. \& Putz, K. (2001). Task 11 Report: Proposal for Objectives and Indicators in Urban Land Use and Transport Planning for Sustainability. PROSPECTS - Procedures for Recommending Optimal Sustainable Planning of European City Transport Systems. TØI Working Report 1183/2001: Oslo.

Muñuzuri, J., Larrañeta, J., Onieva, L., Cortés, P. (2005) Solutions applicableby local administrations for urban logistics improvement. Cities, 22(1), 15-28.

Muñuzuri, J., Cortés, P., Guadix, J., \& Onieva, L. (2012). City logistics in Spain: Why it might never work. Cities, 29(2), 133-141.

Nuzzolo, A. \& Comi, A. (2014). Urban freight demand forecasting: a mixed quantity/delivery/vehicle-based model. Transportation Research Part E: Logistics and Transportation Review, 65, p. 84-98.

Ogden, K. W. (1992). Urban Goods Movement: NA Guide to policy and Planning. Ashgate Publishing Company. Burlington, VT, United States.

Oliveira, G. F. de. (2015). Percepção dos agentes envolvidos na logística urbana em belo horizonte: um estudo exploratório. 2015. 126 f. Dissertação (Mestrado). Curso de Geotecnia e Engenharia de Transportes, Universidade Federal de Minas Gerais, Belo Horizonte. 
ONU. Nações Unidas. (2013). ONU: mais de 70\% da população mundial viverá em cidades até 2050 . Recuperado em 01 de janeiro de 2019, de http://nacoesunidas.org/onu-mais-de-70-da-populacao-mundial-vivera-em-cidades-ate-2050/

Paradeda, D., KRAUS JR, W. \& Carlson, R. (2014). Implantação de Faixas Exclusivas para Ônibus: Efeito da Troca Modal no Tráfego de Automóveis (v. 1. p. 1-12). In: Anais do XXVIII Congresso de Pesquisa e Ensino em Transportes. Rio de Janeiro: Associação Nacional de Pesquisa e Ensino em Transportes - ANPET.

Pfeffer, G. (2018). Niterói, com o pior trânsito, planeja mobilidade. Recuperado em 01 de junho de 2019, de https://www.mobilize.org.br/noticias/10910/niteroi-com-o-pior-transito-planeja-a-mobilidade.html

Pivo, G. et al. (2002). Learning from truckers: truck drivers' views on the planning and design of urban and suburban centers. Journal of Architectural And Planning Research, Chicago, 12-29.

Roumboutsos, A., Kapros, S. \& Vanelslander, T. (2014). Green city logistics: Systems of Innovation to assess the potential of E-vehicles. Research in Transportation Business \& Management, 11, 43-52.

Russo, F. ; Comi, A. (2011) Measures for Sustainable Freight Transportation at Urban Scale: Expected Goals and Tested Results in Europe. Journal of Urban Planning and Development 137(2):142-152 · July 2011

Saaty, T. A, (1977). Scaling method for priorities in hierarchical structures. Journal of Mathematical Psychology, 15, 234-281.

Silva, A. J. da. (2006). Contribuição ao planejamento do transporte urbano de carga pela análise física do espaço urbano. 2006. 148 f. Dissertação (Mestrado). Curso de Engenharia de Transportes, Universidade Federal do Rio de Janeiro, Rio de Janeiro.

Silva, L.; Silva R. da. (2009). Planejamento estratégico de uma experiência pedagógica inovadora. Revista Minerva, 6, 99-106.

Silva, R. C. da. (2012). Contribuição ao planejamento do transporte urbano de carga pela análise física do espaço urbano: estudo da área da rua do catete e largo do machado no Rio de Janeiro. 2012. 88 f. Dissertação (Mestrado). Curso de Pós Graduação em Engenharia de Transportes, Coppe, Universidade Federal do Rio de Janeiro, Rio de Janeiro.

Sinarimbo, N. G. (2005). Freight transport management in the central business district: Na Empirical Analysis of the Trafficand Environmental Impacts of the Cooperative Delivery System. 2005. $233 \mathrm{f}$. Tese (Doutorado). Curso de Logística e Engenharia da Informação, TokyoUniversityOf Marine Science And Technology, Tokyo.

Transport Research \& Innovation Portal. (2004). City Freight: Inter and Intra Urban Freight Distribution Networks. Recuperado em 05 de janeiro de 2019, de https://trimis.ec.europa.eu/project/inter-and-intra-urban-freightdistribution-networks\#tab-results

Visser, J; Van Binsbergen, A; Nemoto, T. (1999). Urban freight transport policy and planning. In: Symposium On City Logistics, 1. Caims. Paper.

WBCSD. Mobility 2030: Meeting the challenges to sustainability. 1111. ed. Aaaa: Wbcsd, 2004. Recuperado em 05 de novembro de 2015, de http://www.wbcsd.org/web/publications/mobility/mobility-full.pdf

\section{Editor: Fábio Duarte}

Recebido: Nov. 06, 2018

Aprovado: Ago. 12, 2019 